\title{
PENGENDALIAN KUALITAS PADA HOME INDUSTRY MOBIL MAINAN TRUCK TANGKI di PT. SELAMAT SENTOSA
}

\author{
Anggi Oktaviani \\ Dosen Program Studi Teknik Industri, FTIK \\ Universitas Indraprasta PGRI Jakarta \\ e-mail: anggi.oktaviani@unindra.ac.id
}

\begin{tabular}{ll}
\hline ARTICLE INFO & ABSTRACT \\
\hline Keywords : & Quality control is conducted so the product or service which are being produced \\
Quality Control, Control & could have a result that matched the standard that are desired and planned, also \\
map, flawed items & to fix product quality which are not matched yet with the standard that already \\
& have been set and wherever possible maintain quality which are fit. Companies \\
& need some way to realize the good quality on products that are they produce \\
& and maintain the consistency so it fulfill the market demands with \\
& implementing quality control system for process activity which is being passed. \\
& Control map is usually being used to map flawed items or the number of flawed \\
& items from a sample which is taken beforehand. In contrast with the p control \\
& map which could map the process with the number of sample in each equal or \\
& inequal observation, np control map could only being used when the taken \\
& sample from each observations have the same amount. This research draws \\
& whether flaw on production process still in the control threshold or not, and \\
& how many size variety ins the controlled threshold or not. After the data \\
processing on PT. Selamat Sentosa, the result shows that attribute control map \\
is not yet on the threshold control that iterarion have to be done and variable \\
control map still on the control threshold. The result shows that CP number is \\
1.8, which is more than 1.33 , so it shows a very good result, dimension which is \\
tolerated is $99.999986 \%$, dimension that reworks is $0.000014 \%$ and dimension \\
that are denied is $0.000007 \%$. Tight control is required because CPK <1.00.
\end{tabular}

\section{PENDAHULUAN}

Dalam meningkatkan kualitas produk dan jasa dibutuhkan pengendalian kualitas (quality control) dari setiap aktivitas yang dijalani. Pengendalian kualitas yang dilakukan adalah dengan memeriksa produk yang memenuhi syarat dan penolakan yang tidak memenuhi syarat sehingga banyak tenaga, material dan waktu terbuang. Mulai 
muncul pemikiran untuk menciptakan sistem yang dapat mencegah adanya masalah mengenai kualitas agar kesalahan yang pernah terjadi, tidak terulang lagi.

Menerapkan sistem pengendalian kualitas yang tepat, mempunyai tujuan dan tahapan yang jelas serta memberikan inovasi (perubahan) dalam melakukan pencegahan dan penyelesaian masalah adalah salah satu aktifitas dalam menciptakan kualitas agar sesuai standar (Ratnadi,2016). Kegiatan pengendalian kualitas dapat membantu perusahaan mempertahankan dan meningkatkan kualitas produknya dengan melakukan pengendalian terhadap tingkat kerusakan produk (product defect) sampai pada tingkat kerusakan nol (zero defect).

Pengendalian kualitas dilakukan agar dapat menghasilkan produk berupa barang atau jasa yang sesuai dengan standar yang diinginkan dan direncanakan, serta memperbaiki kualitas produk yang belum sesuai dengan standar yang telah ditetapkan dan sedapat mungkin mempertahankan kualitas yang telah sesuai. Perusahaan membutuhkan suatu cara yang dapat mewujudkan terciptanya kualitas yang baik pada produk yang dihasilkannya serta menjaga konsistensinya agar tetap sesuai dengan tuntutan pasar yaitu dengan menerapkan sistem pengendalian kualitas (quality control) atas aktivitas proses yang dijalani.

Peta kendali adalah suatu model statistik yang di gunakan untuk mengetahui variasi mutu kualitas produk dalam suatu proses melalui perhitungan peta kontrol untuk mengantisipasi semua kemungkinan variasi dan semua penyebab penurunan mutu. Kualitas yang baik berasal dari suatu proses yang terkendali dan stabil (Prihastono, 2017). Peta kendali memungkinkan deteksi kejadian yang sederhana yang menandakan perubahan proses yang sebenarnya. Keputusan sederhana ini bisa sulit dimana karakteristik proses terus bervariasi peta kendali menyediakan kriteria statistik tujuan dari perubahan. Ketika perubahan terdeteksi dan dianggap baik penyebabnya harus diidentifikasi dan mungkin menjadi cara baru untuk bekerja, di mana perubahan yang buruk maka penyebabnya harus diidentifikasi dan dihilangkan.

Pada penelitian kali ini membahas tentang peta kendali kapasitas variasi pengukuran diameter roda pada komponen mainan truk tangki pada PT Selamat Sentosa dengan menggunakan alat bantu peta kendali dengan perhitungan peta kendali atribut peta kendali variable dan kapabilitas proses untuk mengetahui produksi yang dalam batasan kendali dan mengetahui dimensi yang di terima, di tolak, dan yang harus di kerjakan ulang. Peta kendali atau control chart adalah salah satu alat QC 7 tools (7 alat pengendalian kualitas) yang berbentuk grafik dan dipergunakan untuk memantau atau memonitor stabilitas dari suatu proses serta mempelajari perubahan proses dari waktu ke waktu. Menurut (Kaban,2014) peta kendali memiliki garis atas (Upper Line) untuk Batas Kontrol Tertinggi (Upper Control Line), Garis bawah (Lower Line) untuk garis tengah (Central Line) untuk Rata-rata (Average). Tujuan utama dari penggunaan peta kendali adalah untuk mengendalikan proses produksi sehingga dapat menghasilkan kualitas yang unggul dengan cara mendeteksi

Tujuan utama dari penggunaan Control Chart adalah untuk mengendalikan proses produksi sehingga dapat menghasilkan kualitas yang unggul dengan cara mendeteksi penyebab variasi yang tidak alami (Penyebab Spesial, Penyebab yang tidak Natural) atau disebut dengan process shift (terjadinya penggeseran proses) serta untuk mengurangi variasi yang terdapat dalam proses sehingga menghasilkan proses yang stabil (Ratnadi, 2016). 
Macam macam peta kendali atribut yaitu : Peta kendali fraksi defektif (P-Chart), Peta kendali jumlah defektif (np-chart), Peta kendali jumlah cacat (c-chart).

Peta pengendali proporsi digunakan bila kita memakai ukuran cacat berupa proporsi produk cacat dalam setiap sempel yang diambil. Bila sampel yang diambil untuk setiap kali melakukan observasi jumlahnya sama maka kita dapat menggunakan peta pengendali proporsi kesalahan (p-chart) maupun banyaknya kesalahan (np-chart). Namun bila sampel yang diambil bervariasi untuk setiapkali melakukan observasi berubah-ubah jumlahnya atau memang perusahaan tersebut akan melakukan $100 \%$ inspeksi maka kita harus menggunakan peta pengendali proporsi kesalahan (p-chart).

Peta kendali np biasa digunakan untuk memetakan jumlah item cacat atau banyaknya cacat dari sebuah sampel yang diambil. Berbeda dengan peta kendali p yang dapat memetakan proses dengan jumlah sampel tiap observasi sama maupun tidak sama, peta kendali np hanya biasa digunakan apabila sampel yg diambil tiap observasi jumlahnya sama

Suatu produk dikatakan cacat (defective) jika produk tersebut tidak memenuhi suatu syarat atau lebih. Setiap kekurangan disebut defect. Setiap produk yang cacat bias saja terdapat lebih dari satu defect. (yang diperhatikan banyaknya defect). C pada Peta Kendali atau control chart C Chart menandai "count" atau hitung cacat. Dalam sebuah sampel berapa banyak cacat dijumpai tanpa memperhitungkan jenis cacatnya, segala macam cacat sesuai dengan batasan yang telah dibuat. Misal dalam sebuah proses produksi mungkin terjadi beberapa cacat, pada setiap produk yang dihasilkan, maka jumlah cacat per satuan produk per satuan waktu yang dihitung.

Peta kendali cacat per unit ( $u$-chart) peta kendali u relatif sama dengan peta kendali c. Perbedaanya hanya terdapat pada peta kendali u spesifikasi tempat dan waktu yang dipergunakan idak harus selalu sama, yang membedakan dengan peta kendai c adalah besarnya unit inspeksi perlu diidentifikasikan. U dalam U Chart menandai "Unit" cacat dalam kelompok sampel. Bila dalam teknik yang lain data cacat langsung menjadi data yang diplot ke bagan, maka U Chart perlu untuk menghitung terlebih dahulu U ("Unit”) cacat untuk setiap n, dimana $\mathrm{Ui}=\mathrm{ci} / \mathrm{ni}$. Inilah yang terutama membedakan peta kendali atau control chart U Chart dari C Chart.

Karakteristik ini memberi gambaran mengenai tujuan penggunaan U Chart, yaitu bila dikehendaki observasi dengan inspeksi rutin dengan cara sampling untuk mengetahui kerusakan cacat proses per sampel pada proses produksi dengan volume per satuan waktu tinggi.

Kapabilitas Proses adalah kemampuan suatu proses untuk menghasilkan suatu produk/jasa yang sesuai dengan kebutuhan/syarat dari konsumen atau spesifikasi yang diharapkan. Statistical Process Control (SPC) tidak mampu untuk menganalisa secara kuantitaif suatu proses yang sedang berjalan, karena SPC hanya memantau/memonitor proses yang sedang berjalan. Untuk mengetahui suatu proses berjalan secara capable/tidak (menghasilkan produk/jasa yang sesuai spesifikasinya) dipakailah AKP. Dalam AKP dipakai berbagai nilai indeks untuk mengetahui kualitas dari proses yang dihasilkan.

Tulisan ini menggambarkan apakah kecacatan pada proses produksi masih di dalam batas kendali atau tidak, dan berapa banyak variasi ukuran dalam batas terkendali atau tidak. 


\section{METODOLOGI}

Pelaksanaan penelitian diawali dengan mengumpulkan sumber yang digunakan sebagai acuan yaitu dengan studi ustaka dan studi lapangan di PT. Selamat Sentosa Tbk. Dalam melakukan studi lapangan, peneliti melakukan pengambilan sampel untuk melakukan pengamatan untuk mengetahui produksi yang dalam batasan kendali atau tidak dan belum mengetahui dimensi yang di terima, di tolak, dan yang harus di kerjakan ulang. Melakukan pengamatan sebanyak 22 hari waktu kerja dalam sebulan dengan sampel sebanyak 8 dan 16, selanjutnya C produk cacat yang di temukan mengunakan alat bantu peta kendali atribut dan variabel.menggunakan peta kendali atribut dan peta kendali variabel, peta dan kapabilitas proses.

Langkah yang terakhir menganalisa hasil yang sudah di dapatkan pada pengolaha data sesuai dengan yang diharapkan atau tidak. Dapat mengevaluasi setiap kinerja dan pengaruh dalam usaha pengendalian kualitas sebagai feedback untuk recana selanjutnya

\section{HASIL DAN PEMBAHASAN}

1. Pengumpulan data

Pada Divisi Quality Control PT Selamat Sentosa Tbk melakukan pemeriksaan terhadap produk mainan truk tangki di lakukan pengambilan sampel sebanyak 22 hari kerja dengan kecacatan lebih dari 3 dianggap NG. dengan nilai $\mathrm{N}$ adalah 22 pada peta kendali atribut dan nilai $\mathrm{n}$ adalah 8 dan 16 pada peta kendali variabel dan didapatkan nilai variasi besaran komponen pada data seven tools.

2. Pengolahan Data

a. Peta Kendali Atribut

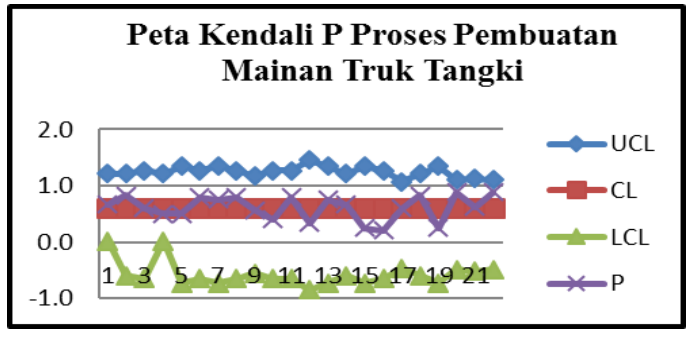

Gambar 1. Peta kendali atribut

Di dapatkan pada peta kendali P nilai UCL adalah 1.2, nilai CL adalah 0.61 dapat dilihat bahwa grafik bergerak secara periodik grafik mengalami kecenderungan naik turun namun dalam batas terkendali. 


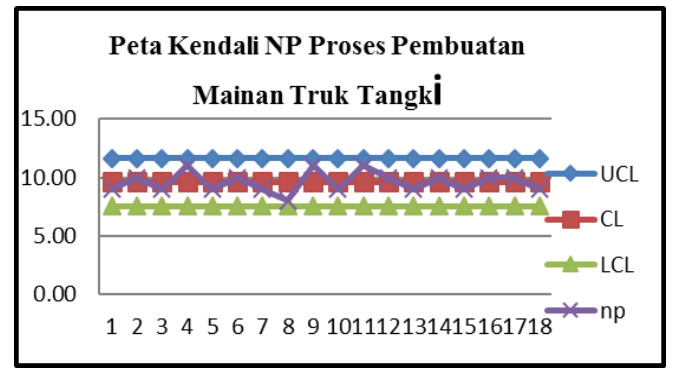

Gambar 2. Peta kendali NP

Di dapatkan pada peta kendali NP setah iterasi 2 kali nilai UCL adalah 11.65, nilai CL adalah 9.61 dan LCL adalah 7.57 dapat dilihat bahwa grafik bergerak secara periodik grafik mengalami kecenderungan naik turun namun dalam batas terkendali.

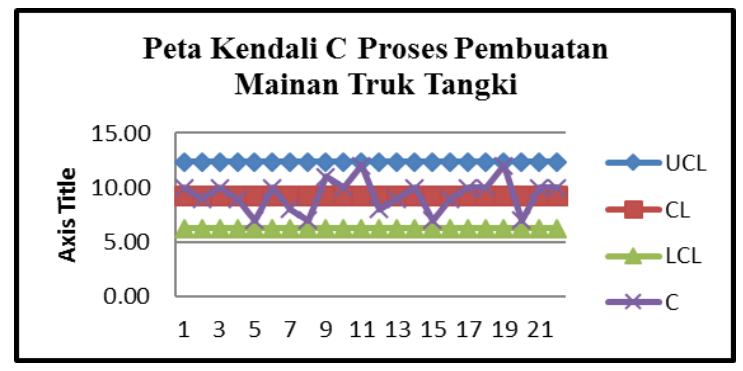

Gambar 3. Peta kendali C

Setelah melakukan iterasi sebanyak satu kali maka di dapatkan pada peta kendali C nilai UCL adalah 12.11, nilai CL adalah 9.09 dan LCL adalah 6.08 dapat dilihat bahwa grafik bergerak secara periodik grafik mengalami kecenderungan naik turun namun dalam batas terkendali.

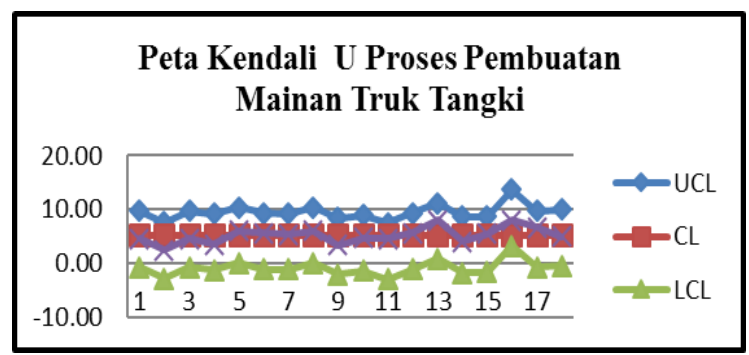

Gambar 4. Peta kendali U

Setelah melakukan iterasi sebanyak satu kali maka di dapatkan pada peta kendali U, denga nilai CL adalah 5.11 dan dapat dilihat bahwa grafik bergerak mendekati pusat dalam batas terkendali. 
b. Peta Kendali Variabel

1) Peta kendali $X$ bar $R$

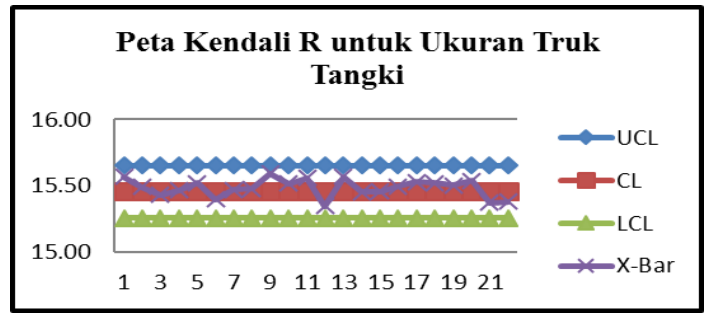

Gambar 5. Peta kendali R

Di ketahui nilai $\mathrm{A}_{2}$ adalah 0,373 nilai $\mathrm{D}_{4}$ adalah 1,864 dan nilai $\mathrm{D}_{3}$ adalah 0.136 di dapatkan nilai $\mathrm{CL}$ adalah 15.45 nilai UCL adalah 15.65 dann nilai LCL adalah 15.26 dan dapat dilihat bahwa grafik bergerak mendekati pusat dalam batas terkendali.

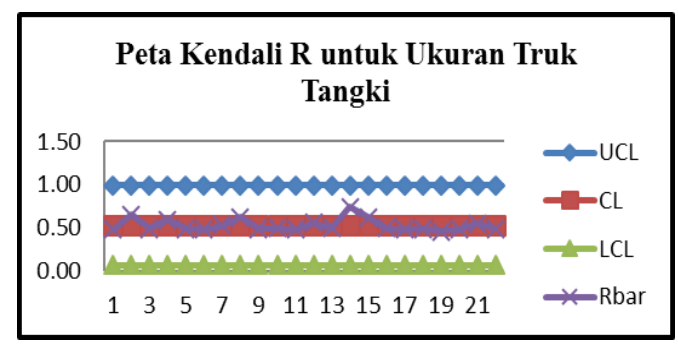

Gambar 6. Peta kendali R

Di ketahui nilai $\mathrm{A}_{3}$ adalah 0,373 nilai $\mathrm{B}_{4}$ adalah 1,864 dan nilai $\mathrm{B}_{3}$ adalah 0.448 di dapatkan nilai $\mathrm{CL}$ adalah 32.41 nilai UCL adalah 35.6 dann nilai LCL adalah 29.2 dan dapat dilihat bahwa grafik bergerak Over Control .

2) Peta Kendali $X$ bar $S$

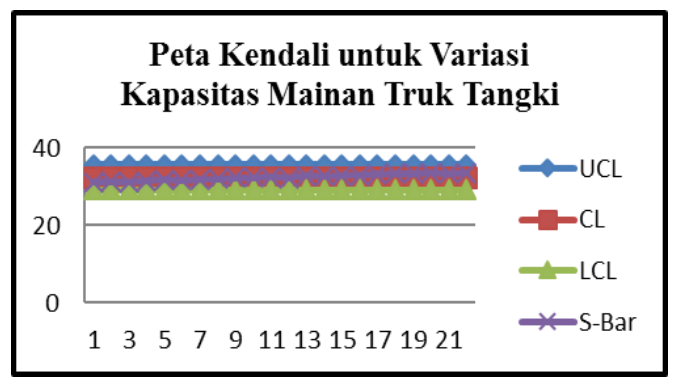

Gambar 7. Peta kendali variasi kapasitas mainan truk tangki

Di ketahui nilai $\mathrm{A}_{3}$ adalah 0,763 nilai $\mathrm{B}_{4}$ adalah 1.552 dan nilai $\mathrm{D}_{3}$ adalah 0.448 di dapatkan nilai $\mathrm{CL}$ adalah 34.21 nilai UCL adalah 35.6 dann nilai LCL adalah 29.2 dan dapat dilihat bahwa grafik bergerak Over Control . 


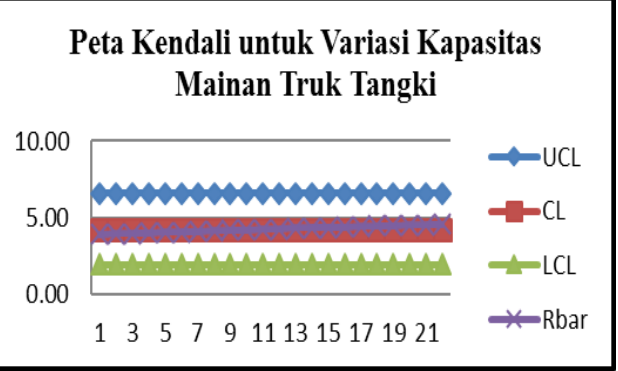

Gambar 8. Peta kendali variasi kapasitas mainan truk tangki

Di ketahui nilai $\mathrm{A}_{3}$ adalah 0,763 nilai $\mathrm{B}_{4}$ adalah 1.552 dan nilai $\mathrm{D}_{3}$ adalah 0.448 di dapatkan nilai $\mathrm{CL}$ adalah 4.23 nilai UCL adalah 6.57 dann nilai LCL adalah 1.90 dan dapat dilihat bahwa grafik bergerak Over Control .

c. Kapabilitas Proses

Didapatkan hasil bahwa nilai CP lebih besar dari 1.33 maka sangat baik. Di dapatkannya nilai Z1 = 5.25 dan Z2 adalah -5.26 dimensi yang di terima adalah 99.999986\% dimensi yang bekerja ulang adalah $0.000014 \%$ dan dimensi yang ditolak adalah 0.000007\%.Di perlukannya pengendalian ketat karena CPK $<1,00$.

\section{SIMPULAN}

Telah dilaksanakan pengolahan data dapatan hasil bahwa peta kendali atribut belum dalam batas kendali harus di lakukannya iterasi dan peta kendali variabel, masih dalam batas kendali. Didapatkan hasil bahwa nilai CP adalah 1.8 lebih besar dari 1.33 maka sangat baik. dimensi yang di terima adalah $99.999986 \%$ dimensi yang bekerja ulang adalah $0.000014 \%$ dan dimensi yang ditolak adalah $0.000007 \%$.Di perlukannya pengendalian ketat karena CPK $<1,00$.

Setelah dianalisa, grafik pada peta kendali atribut mengalami pergerakan secara periodik kecenderungan naik turun namun masih dalam batas kendali dan pada peta kendali variabel mengalami over control. 


\section{DAFTAR PUSTAKA}

Arief, I., \& Fajri, R. (2015). Perancangan Purwarupa Sistem Pengendalian Kualitas Pengukuran Dimensi Produk Terotomasi. Jurnal Optimasi Sistem Industri, 14(2), 217-226.

Kaban, R. (2014). Pengendalian Kualitas Kemasan Plastik Pouch Menggunakan Statistical Procces Control (SPC) di PT Incasi Raya Padang. Jurnal Optimasi Sistem Industri, 13(1), 518-547.

Prihastono, E., \& Amirudin, H. (2017). Pengendalian Kualitas Sewing di PT. Bina Busana Internusa III Semarang. Jurnal Ilmiah Dinamika Teknik, 10(1).

Ratnadi, R., \& Suprianto, E. (2016). Pengendalian Kualitas Produksi Menggunakan Alat Bantu Statistik (Seven Tools) Dalam Upaya Menekan Tingkat Kerusakan Produk. Jurnal Industri Elektro dan Penerbangan, 6(2).

Sinambela, S., \& Lahudin, A. H. (2015). Usulan Penggunaan Six Sigma Untuk Peningkatan Kualitas Proses Produksi Di Pt. Ao. Faktor Exacta, 7(1), 37-58. 